\title{
Impact of Environmental Complexity and Stocking Density on Affective States of Rainbow Trout (Oncorhynchus Mykiss)
}

\section{M.G. Anderson}

Virginia Tech

\author{
A.M. Campbell \\ Virginia Tech \\ D.D. Kuhn \\ Virginia Tech \\ S.A. Smith \\ Virginia-Maryland College of Veterinary Medicine \\ L. Jacobs ( $\nabla$ jacobsl@vt.edu ) \\ Virginia Tech
}

\section{Research Article}

Keywords: animal welfare, rainbow trout, environmental complexity, enrichment, stocking density, affective state

Posted Date: April 7th, 2021

DOI: https://doi.org/10.21203/rs.3.rs-387346/v1

License: (c) (1) This work is licensed under a Creative Commons Attribution 4.0 International License. Read Full License

Version of Record: A version of this preprint was published at Animal Cognition on April 16th, 2022. See the published version at https://doi.org/10.1007/s10071-022-01616-6. 


\section{Abstract}

Affective states of animals can be assessed through judgement bias tests, evaluating responses to ambiguous situations. In this study, rainbow trout $(n=108)$ were housed in recirculating aquaculture systems under commercial conditions while trained at tank-level to discriminate between a positively reinforced chamber (feed) in one location and a negative chamber (positive punishment; chase by net for 1s) in the opposing location. Fish from successful tanks ( 2 out of 5 tanks) were then housed in treatment tanks of either high or low environmental complexity at either high $\left(165 \mathrm{fish} / \mathrm{m}^{3}\right)$ or low $\left(69 \mathrm{fish} / \mathrm{m}^{3}\right)$ stocking density. Trained fish were tested for latencies to approach three intermediate, ambiguous chambers. Fish housed in high-density tanks were faster to enter all chambers than those housed in low-density tanks (8.5s vs. 15.2s; $P=0.001)$, with faster entries into the positive (7.4s vs. $15.2 \mathrm{~s} ; P=0.02)$ and near-negative chambers (10.2s vs. $17.4 \mathrm{~s} ; P=$ 0.006), suggesting that these fish were more optimistic to receive a feed reward. Tank complexity did not affect test outcomes. No differences between treatments were observed between body weight, length, and plasma cortisol. Overall, rainbow trout are capable of discriminating between cues during a judgement bias test and fish housed in high-density environments respond more optimistically in ambiguous situations compared to fish in low-density environments.

\section{Introduction}

The welfare of terrestrial livestock has undergone much study, partly because of a push from concerned consumers. However, relatively little has been investigated about the welfare of our aquatic food sources. Rainbow trout (Oncorhynchus mykiss) are typically housed in a variety of barren ponds, raceways, or recirculating aquaculture systems ${ }^{1}$. These environments provide no access to biologically-relevant enrichments, besides that of interaction with conspecifics. Environmental complexity can have a positive impact on animals' biological functioning and behavior ${ }^{2,3}$. For example, rainbow trout reared in enriched environments with cobblestone tank substrate had better fin condition, and steelhead trout (Oncorhynchus mykiss irideus) housed in tanks with unmoved rocks exhibited more exploratory behavior than fish in a barren control environment ${ }^{4,5}$. Stocking density is another environmental aspect to consider, but guidelines differ due to the complex interactions between density, fish behavior, fin damage, availability of feed, and type of rearing system ${ }^{6-8}$. High stocking densities could indirectly affect fish welfare through reduced water quality, decreased growth rate, and competition for feed $6,7,9,10$. Therefore, it is important to consider the effect of stocking density, in addition to environmental complexity, on fish health and welfare.

Fish can experience negative emotions, such as pain, fear, and suffering, just like their terrestrial counterparts, through systems similar to the prefrontal cortex ${ }^{11-13}$. These short-term emotions are adaptive and allow the animal to appropriately respond to changing environments ${ }^{14}$. Short-term emotional responses can shape an animal's affective state, which are long-term states that reflect the cumulative valence of emotions over time ${ }^{15}$. Affective states can influence the way an animal makes decisions (cognitive bias) ${ }^{16-24}$. Cognitive bias tests are a well-validated indicator of animal welfare for a variety of terrestrial species, however there is little evidence of this type of test being employed in an aquatic setting for farmed fish ${ }^{14,25,26}$. One type of cognitive bias test measures a subject's judgement bias through responses to ambiguous cues, which is then used to determine the subject's level of optimism or pessimism. Shorter latencies to approach ambiguous cues would indicate 
optimism (greater expectation of a reward), whereas longer latencies to approach ambiguous cues would indicate pessimism (lower expectation of a reward) ${ }^{14,15,27-29}$. Ultimately, the judgement bias test has been considered the "gold standard" for evaluating affective states in animals and could be a valid tool to assess fish welfare ${ }^{30}$.

Environmental complexity has the potential to positively impact fish welfare and affective states. Providing shelter structures has been shown to decrease aggression, fin erosion, and distress in Atlantic salmon (Salmo salar) and rainbow trout, possibly because fish have the opportunity to escape bullies ${ }^{4,31-33}$. Artificial vegetation decreased the frequency of startle responses in Tiger Muskellunge (Esox masquinongy $\mathrm{x}$ Esox lucius) and reduced the habituation period for bream (Abramis brama) in experimental conditions ${ }^{34,35}$. Additionally, providing floating artificial vegetation can serve as partial visual cover, which is preferred over unshaded areas, and can increase growth rate and decrease stress of Atlantic salmon ${ }^{36,37}$. Based on prior findings, providing environmental complexity within the tank could lead to a reduction of emotions associated with a negative affective state and induce an overall positive affective state.

Affective states of zebrafish (Danio rerio) housed in different environments were successfully evaluated through a judgement bias test ${ }^{38}$. Zebrafish housed in enriched tanks showed more exploratory behavior within ambiguous cues than those housed in barren tanks, suggesting affective state was manipulated by environmental conditions. Additionally, female cichlid fish (Cichlidae) housed with non-preferred males showed pessimistic responses during a judgment bias test ${ }^{24}$. Based on these studies, judgement bias tests could be a useful tool to assess affective states of rainbow trout housed under varying environmental conditions, however this has not yet been employed.

The objective of this study was to evaluate the effects of environmental complexity and stocking density on affective states of rainbow trout through a judgement bias test. Additional measurements were taken, such as individual weight and length to evaluate potential impact of housing environments on production outcomes, feeding behavior, and plasma cortisol to assess fish stress levels. We hypothesized that fish reared in highcomplexity tanks of either high- or low-density would exhibit increased optimism in the judgement bias test through shorter latencies to approach ambiguous cues compared to fish reared in low-complexity tanks of either density. We also expected weight and length of fish from high-complexity, low-density tanks to be greater than fish from any other treatment group. We expected fish housed in high-density tanks of either complexity level to show the shortest latencies to begin feeding compared to all other treatment groups because of increased competition for feed. Lastly, it was hypothesized that fish housed in high-complexity, low-density tanks would show decreased stress when compared to all other treatment groups.

\section{Materials And Methods}

\section{Ethics}

This experiment was approved by Virginia Tech's Institutional Animal Care and Use Committee (20-074) and was conducted in the Department of Food Science and Technology's aquaculture facility at Virginia Tech's Human, Agriculture, and Biosciences Building I from August to December 2020. This experiment was performed in accordance with the Institutional Animal Care and Use Committee's relevant guidelines and regulations. 


\section{Subjects and housing}

Rainbow trout ( $\mathrm{n}=108 ; \mathrm{F} 1$ generation Shasta strain) were bred and hatched in January 2020 and cultured at the Wytheville State Fish Hatchery (Wytheville, VA). In August 2020, fingerlings were transported to the research facility in 2 tanks of $14.1^{\circ} \mathrm{C}$ water. Upon arrival, fingerlings were acclimated to the recirculating aquaculture system water conditions $\left(13.3^{\circ} \mathrm{C}\right)$ and facility management for 4 weeks. No mortalities were observed during or 24 hours post-transportation. On day 1 of the experiment, fish were distributed across 5 tanks $(45.7 \times 73.7 \mathrm{x}$ $21.6 \mathrm{~cm}$; water volume $=0.0726 \mathrm{~m}^{3}$ ) under commercial conditions with 21,22 , or 23 fish in each tank. Temperature, dissolved oxygen level, ammonia- $\mathrm{N}$, nitrite- $\mathrm{N}$, nitrate- $\mathrm{N}, \mathrm{pH}$, and alkalinity were monitored at least once per week. All water quality parameters remained within suitable ranges ${ }^{64,65}$, with the exception of alkalinity, which dropped below the optimal range on day 3 . Sodium bicarbonate was added to the system throughout the trial to maintain optimal alkalinity values. Fish were fed a commercial trout diet ( $3 \mathrm{~mm}$ Finfish Gold, Zeigler Bros Inc., Gardner, PA, USA) once daily ad libitum. A subsample of fish ( $n=72)$ were tagged with Tbar tags (Floy Tag, WA, USA) after sedation with sodium bicarbonate buffered MS-222 (Syndel, Ferndale, WA, USA) on days $1-3^{66}$.

\section{Treatments}

This experiment involved a 2' 2 factorial design using environmental complexity and stocking density as factors, resulting in 4 treatment groups: HC/HD, HC/LD, LC/HD, and LC/LD. All fish $(n=108)$ were kept under the same commercial conditions ( 5 tanks) until day 64 of the experiment. During this time, all fish were trained on a judgement bias task at tank level. After the judgement bias training was completed and on day 64,40 fish from the 2 tanks that were successfully trained were allocated to 8 treatment tanks ( 5 successfully trained fish/treatment tank). Tags of successfully trained fish were marked with black marker $(n=40)$ to differentiate them from fish that were not successfully trained, most importantly in HD tanks. Three arbitrarily selected fish from the 2 successfully trained tanks were excluded from the experiment to achieve an even distribution of successfully trained fish across the 8 treatment tanks. Twenty-eight fish from the remaining 3 tanks that did not meet the learning criterion were arbitrarily selected and evenly distributed across 4 of the 8 tanks for the HD treatment $(n=7$ randomly selected fish/HD tank). The remaining fish $(n=37)$ were excluded from the experiment. Thus, from days 1-64 all fish were kept under commercial conditions in 5 tanks, then a subsample of fish $(n=68)$ were redistributed over 8 treatment tanks in which they remained until day 96 (Figure 4).

Four tanks provided a complex environment $(\mathrm{HC})$, while the other four tanks provided a simple environment similar to commercial standards (LC). HC tanks contained one PVC shelter structure (cut in half, $10.2 \mathrm{~cm}$ diameter, $15.2 \mathrm{~cm}$ long), which was placed at the bottom of the tank, two artificial floating lily pads $(17.5 \mathrm{~cm} \mathrm{x}$ $17.0 \mathrm{~cm}$, Amazon.com, Inc., WA, USA), and two artificial cabomba plants (17.8cm, AquaTop, CA, USA). Enrichment objects were removed and disinfected daily. LC tanks contained no enrichment objects.

Based on the mean fish weight of $287 \mathrm{~g}$ at day 96 and the Food and Agriculture Organization of the United Nations guidelines ${ }^{1}, 4$ tanks $(H C=2 ; L C=2)$ were stocked at a high-density $(H D)$ of 12 fish $\left(165 \mathrm{fish} / \mathrm{m}^{3}\right)$. The other 4 tanks $(H C=2 ; L C=2)$ were stocked at a low-density $(L D)$ of $5 \mathrm{fish}\left(69 \mathrm{fish} / \mathrm{m}^{3}\right)$.

\section{Judgement bias test}


The judgement bias process followed a 7-step approach (habituation; training: phase 1, phase 1A, phase 2, phase 3; reminder training; and testing; Table 2) and took place in the home tanks, at tank-level. All steps of the judgement bias test were performed using a removable plexiglass arena with 5 equally-distanced opaque blue chambers and sliding doors (Figure 5). Sliding doors allowed for the experimenter to provide or deny access to each of the 5 chambers in the arena.

Habituation to the judgement bias arena without sliding doors was performed with all fish within a tank $(n=21$ $23 \mathrm{fish} / \operatorname{tank}$ ), including the subsample of tagged fish (Table 2). A single experimenter gently placed the arena in the tanks from days 13-31 for 9 habituation sessions. For the first 4 sessions, the arena was placed into each tank for $5 \mathrm{~min}$ with the experimenter out of sight. For the following 3 sessions, the arena was placed and the experimenter remained in line of sight for $15 \mathrm{~min}$ per session. During the last 2 sessions, the arena was placed and the experimenter sprinkled feed into the tank, remaining in line of sight for $15 \mathrm{~min}$ per session.

Training phases 1-3, reminder training, and testing involved placing the arena into each tank with the sliding doors closed for $3 \mathrm{~min}$ to allow fish to acclimate. If a fish entered the POS chamber within any $15 \mathrm{~s}$ attempt during phases $1-3$, feed was immediately placed into the chamber and fish were allowed 10 s to feed. After every attempt, the chamber door was closed and remaining feed was removed. Habituation and phases 1-3 were performed while fish were housed in commercial conditions ( $n=21-23$ fish/tank), while reminder training and testing took place while fish were housed under treatment conditions (Table 2).

Phase 1 of training was performed at tank-level (Table 2). Fish in each tank ( $n=21-23$ fish/tank) were trained to associate a chamber on either the far left ( 3 tanks) or far right ( 2 tanks) side of the arena with a reward (POS; approximately 30 feed pellets). If no fish entered the chamber within $15 \mathrm{~s}$, feed was placed into the chamber and 10s was allowed for fish to enter and feed. The learning criterion for phase 1 was met when at least 1 fish entered the POS chamber within 15s for 9 out of 12 attempts during two consecutive phase 1 training sessions. Two tanks passed the learning criterion for phase 1 of training between days 38 and 58, the other three tanks moved on to phase $1 \mathrm{~A}$ of training, as the fish were not close to meeting the learning criterion after 5 sessions. Training phase $1 \mathrm{~A}$ was similar to phase 1, however, fish were rewarded with feed if they oriented towards or swam within $15 \mathrm{~cm}$ of the POS chamber opening. Tanks returned to phase 1 of training once at least $1 \mathrm{fish}$ entered the POS chamber within 15s during two consecutive phase $1 \mathrm{~A}$ training sessions. Only one tank met the learning criterion for phase $1 \mathrm{~A}$ and returned to phase 1 on day 46 , meeting the phase 1 learning criterion on day 47. The other two tanks remained in phase $1 \mathrm{~A}$ until day 57 , when they were excluded from the judgement bias task due to unresponsiveness.

Phase 2 of training with the remaining three tanks was aimed to habituate fish to being in a smaller group within their tank (approximately 10 fish/group; 2 groups/tank; Table 2). Half of the fish (group 1) were gently herded to the side of the tank containing the arena and separated from their conspecifics (group 2) by placing a blue opaque plexiglass separator into the middle of the tank. Then, the POS chamber door was opened. If no fish entered the chamber within the first 15s attempt, feed was placed into the chamber and fish were allowed 10 s to enter and feed. If no fish entered during any of the following 15 s attempts, the chamber door was immediately closed and the next attempt began. If a fish entered the chamber within any of the $15 \mathrm{~s}$ attempts, feed was immediately placed into the chamber and fish were allowed 10s to feed. After group 1, group 2 underwent the same training session. Phase 2 learning criterion was met when at least one fish in both groups 1 and 2 entered the POS chamber within 15s and consumed feed in 9 out of 12 attempts during two 
consecutive phase 2 sessions. All three tanks passed the learning criterion for phase 2 of training between days 45 and 59 .

In training phase 3 , the negative chamber was introduced (NEG; net placed in water for 1s; Table 2). NEG and POS cue presentations were pseudorandomized according to a predetermined order, never allowing more than two consecutive presentations of the NEG or POS cue, and began and ended with the POS cue. Half of the fish (group 1; approximately 10 fish) were gently herded to the side of the tank containing the arena and separated from their conspecifics (group 2; approximately 10 fish) by placing the blue opaque plexiglass separator into the middle of the tank. Then, the POS chamber door was opened. If a fish did not enter within $15 \mathrm{~s}$, the door was immediately closed. When the NEG chamber was opened, fish were allotted $15 \mathrm{~s}$ to enter the chamber. If a fish entered within $15 \mathrm{~s}$, a green net was placed into the water for approximately $1 \mathrm{~s}$, then the chamber door was closed. If no fish entered within 15s, the chamber door was immediately closed. After 6 attempts ( 1 session) for group 1, group 2 was trained. Phase 3 learning criterion was met when at least one fish from both groups enter the POS chamber $100 \%$ of the time it was accessible and neglected to enter the NEG chamber $100 \%$ of the time it was accessible during two consecutive phase 3 training sessions. Two tanks passed the learning criterion for phase 3 on day 61 . The third tank was excluded from the judgement bias task due to time constraints.

The trained subsample of fish (HD) or all fish (LD) underwent weekly reminder training sessions identical to phase 3 of training (Table 2). In HC tanks, enrichment objects were removed prior to a session.

Each of the 8 tanks ( $n=38$ fish) were tested for judgement bias three times on days 92, 93, and 95 (Table 2). In addition to the POS and NEG cues, three ambiguous cues (near positive, NP; middle, MID; near negative, NN) were individually presented at intermediate locations within the arena (near left, middle, and near right; Figure 2). Each ambiguous cue was presented once per session according to a pre-determined order. Fish were given 20 s to enter an opened chamber. Testing always began and ended with the POS cue, which was presented 8 times with fish receiving a feed reward if they entered the chamber. The NEG cue was presented 4 times and if a fish entered the chamber, it was chased by a net for $1 \mathrm{~s}$. All ambiguous cues were neither rewarded nor punished. For $\mathrm{HC}$ tanks, enrichment objects were removed prior to testing. In HD tanks, the tagged subsample of fish was separated from the other 7 fish with a blue plexiglass separator throughout testing. Fish were allowed $3 \mathrm{~min}$ to acclimate. Latency for the first fish to enter each chamber (s) was recorded. A maximum latency score of 20 s was appointed to attempts during which no fish entered the chamber.

\section{Body weight and standard length}

On days $64(n=68)$ and $96(n=66)$, individual weights and lengths were recorded. On day 96, only 66 fish were weighed and measured due to 2 mortalities. Fish were individually netted and placed into a buffered MS-222 water bath (sedation strength of $75-100 \mathrm{mg} / \mathrm{L}$ ) for approximately $5 \mathrm{~min}$ or until sedated ${ }^{66}$. After sedation, the fish was placed on a scale (PTS3000, $0.1 \mathrm{~g}$ precision, PESOLA, CH, USA) and then beside a ruler to measure standard length (from the tip of the nose to the base of the caudal fin). Then, the fish was immediately placed in a fresh water recovery tank where it was monitored until normal swimming behavior resumed. At this point, the fish was placed back into the home tank.

\section{Feeding behavior}


Latency to begin feeding was assessed at tank level on days 79-95 (observation $n=128$ ). During daily feeding, the observer sprinkled a handful of feed into the tank and immediately started a timer. Latency until the first fish began feeding (s) was recorded for each tank once daily.

\section{Plasma cortisol}

On day 96 , blood was collected from the 38 fish trained on the judgement bias task $(n=4-5 / \operatorname{tank})$. Fish $(n=38)$ were individually netted and placed into a buffered MS-222 water bath (sedation strength of $75-100 \mathrm{mg} / \mathrm{L}$ ) for approximately $5 \mathrm{~min}$ or until sedated ${ }^{66}$. After sedation, the fish was placed on a wetted work table and bled from the caudal tail vessel using a 23-gauge needle and syringe. Approximately $0.5-1.0 \mathrm{~mL}$ of blood was obtained, then the fish was immediately euthanized by an overdose of buffered MS-222 (euthanasia strength of $250 \mathrm{mg} / \mathrm{L}$ ). Blood was placed in heparinized tubes and kept on ice until centrifugation. Samples were centrifuged at $3000 \mathrm{xg}$ for $10 \mathrm{~min}$ at $12^{\circ} \mathrm{C}$, then plasma was stored at $-80^{\circ} \mathrm{C}$ until ELISA analysis using a commercial cortisol express ELISA kit (Cayman Chemical, Ann Arbor, MI, USA). The ELISA was performed following the manufacturer protocol. Four of 38 samples were excluded from the statistical analysis due to unreliable assay results.

\section{Statistical analysis}

All data were analyzed in JMP pro 15 (SAS Institute Inc., Cary, NC, USA). Judgement bias data residuals were deemed normally distributed based on visual examination of normal quantile plots. Mixed models were used with complexity, stocking density, and test session as fixed factors, tank as a random factor, and latency to enter each chamber as the response variable. There was an effect of stocking density on latencies, so we blocked the analysis by chamber type (POS, NP, MID, NN, NEG) to assess the effect of density on latencies for each separate chamber. Tukey HSD post-hoc comparisons were used to evaluate pairwise differences. Length and weight data residuals were normally distributed and analyzed using mixed models, with environmental complexity and stocking density as fixed factors and tank as a random factor. Latency to begin feeding data were log10 transformed to obtain a normal distribution of data residuals and are presented as raw means. Then, mixed models were used with environmental complexity and stocking density as fixed factors and tank as a random factor. Data are presented as least squares means \pm standard error unless otherwise noted.

\section{Results}

\section{Judgement bias test}

After 32 days, fish kept in high-complexity/high-density (HC/HD), high-complexity/low-density (HC/LD), lowcomplexity/high-density (LC/HD), and low-complexity/low-density (LC/LD) treatments were tested for judgement bias, measuring latencies to enter the positive (POS), negative (NEG), and 3 ambiguous chambers (near positive, NP; middle, MID; near negative, NN). Mean latencies to enter all chambers were $10.91 \pm 1.59 \mathrm{~s}$ for test session $1,11.94 \pm 1.59$ s for test session 2 , and $12.55 \pm 1.59$ s for test session 3 . Testing session did not impact responses of fish during the judgement bias test $\left(F_{1,2}=0.973 ; P=0.380\right)$.

Environmental complexity did not affect latencies for fish to enter all chambers during the judgement bias test $(H C=11.76 \pm 0.95 s ; L C=11.84 \pm 0.95 s ; P=0.955)$. Furthermore, environmental complexity did not impact 
latencies to enter the POS $\left(F_{1,6}=0.02 ; P=0.891\right), N P\left(F_{1,6}=0.11 ; P=0.752\right), M I D\left(F_{1,6}=0.173 ; P=0.692\right), N N$ $\left(F_{1,6}=1.026 ; P=0.35\right)$, or NEG $\left(F_{1,6}=0.121 ; P=0.739\right)$ chambers (Table 1$)$. There was no interaction effect of chamber type and complexity level on latencies to enter all chamber cues $\left(F_{1,148}=0.699 ; P=0.594\right)$.

Fish housed in HD tanks were faster to enter the test chambers than fish housed in LD tanks (HD $=8.45 \pm 0.91 \mathrm{~s}$; $L D=15.2 \pm 0.91 \mathrm{~s} ; \mathrm{P}=0.001)$. Fish from HD tanks were faster to enter the $N N\left(F_{1,6}=20.3 ; P=0.006\right)$ and $P O S$ $\left(F_{1,6}=10.797 ; P=0.022\right)$ chambers compared to fish from LD tanks (Figure 1). Additionally, fish from HD tanks tended to enter the MID $\left(F_{1,6}=4.68 ; P=0.083\right)$ and NP $\left(F_{1,6}=5.075 ; P=0.074\right)$ chambers faster than fish from LD tanks. There were no pairwise differences in latency to enter the NEG chamber $\left(F_{1,6}=3.118 ; P=0.138\right.$; Figure 1).

\section{Body weight and standard length}

There was no effect of environmental complexity or stocking density on body weight and length of fish on day 64 or 96 ( $P>0.1$; Figure 2$)$.

\section{Feeding behavior}

Environmental complexity did not impact latencies to begin feeding during daily feedings $\left(F_{1,15}=0.161 ; P=\right.$ 0.709; Figure 3a). However, fish housed in high-density tanks had shorter latencies to begin feeding than fish housed in low-density tanks $\left(F_{1,15}=13.9 ; P=0.0203\right.$; Figure $\left.3 b\right)$.

\section{Plasma Cortisol}

Cortisol concentrations did not differ between treatment groups $(P>0.1)$. Mean cortisol concentrations were $1.16 \mathrm{ng} / \mathrm{mL}$ for HD, $3.68 \mathrm{ng} / \mathrm{mL}$ for LD, $3.09 \mathrm{ng} / \mathrm{mL}$ for HC, and 1.74 ng/mL for LC fish (standard error = 1.10; $\mathrm{n}$ $=34)$.

\section{Discussion}

This study is the first to apply a judgement bias test to evaluate affective states of rainbow trout. While housed in commercial conditions, fish were trained at tank-level to discriminate between two opposing locations of an arena, with one location associated with a feed reward and the other location associated with being chased by a net. After 61 days of training, two of the five tanks successfully passed the learning criterion to be tested. Then, affective state was manipulated by placing fish in either high- or low-complexity tanks under either highor low-density. Fish from HD tanks were faster to enter all chambers than fish from LD tanks, and had shorter latencies to enter the NN and POS chambers, suggesting optimism for a reward in the fish from HD tanks. Environmental complexity did not affect latencies to enter chambers during the judgement bias test, suggesting environmental complexity had no impact on fish affective state or optimism in this study.

The lack of impact of the environmental complexity treatment was opposite to our hypothesis. We provided environmental enrichments that were biologically relevant and ultimately improved trout affective state through rearing them in an environment closest to that of their natural living conditions ${ }^{2}$. In their natural habitat, rainbow trout will seek cover in the form of overhanging vegetation, undercut banks, aquatic vegetation, logs, or 
debris piles to rest and avoid predation ${ }^{39}$. We used artificial floating lily pads as visual cover because it has been shown that rainbow trout prefer darker areas of a tank environment over exposure to bright lights, and seek safety in these areas when in the presence of a threatening stimulus ${ }^{40,41}$. Additionally, a PVC shelter structure was provided, because the presence, not necessarily the utilization, of shelters reduced basal cortisol and metabolic rates in Atlantic salmon ${ }^{33,42}$. Finally, artificial cabomba plants were used to simulate aquatic vegetation, a form of shelter used by wild rainbow trout fry ${ }^{39}$. Similar environmental enrichments (shelter and gentle light) for zebrafish resulted in more optimistic responses during the judgement bias test compared to the control, with more exploratory behavior within the ambiguous cues (28\% of observed time compared to $7.5 \%)^{38}$. Social enrichment for cod (Gadus morhua) affected their cognitive bias; cod housed with a larger, more aggressive conspecific for 24 hours were 12 times less likely to enter ambiguous chambers during a judgement bias test compared to fish housed in social isolation for 24 hours ${ }^{21}$. Similarly, female cichlids housed with an unpreferred male showed longer latencies to respond to the ambiguous signal than females housed with a preferred male (approximately 600s versus 300s) ${ }^{24}$. These studies show that judgement bias can be influenced by environmental conditions, however it is possible that fish in our study were not exposed to the enrichments for long enough to observe any effect on affective state, with 3 weeks of exposure prior to judgement bias testing in our study compared to 7-18 weeks in previous work. Alternatively, the effect of density might have overshadowed any potential effect of environmental complexity. Perhaps the LD treatment was too great of a stressor that environmental complexity could not alleviate that stress. Similarly, the HD environment may have provided such a welfare benefit that environmental complexity could not contribute further to trout responses.

To our knowledge, there are no published studies investigating the effects of stocking density on affective states of trout. During testing, fish from HD tanks were overall more optimistic than fish in LD tanks, and specifically more optimistic to receive a reward in the NN chamber. Fish from HD tanks also tended to be more optimistic to receive a reward in the MID and NP chambers than fish from LD tanks. We hypothesized that access to more space was preferable over large group sizes, yet our results indicate the contrary. Little is known about the preferred group sizes of rainbow trout in a semi-natural setting ${ }^{43,44}$. In the wild, however, low population densities often result in territorial defense and dominant fish driving out subordinate fish from a preferred area, while higher population densities lead to the formation of fish aggregates ${ }^{39}$. Therefore, it is possible that fewer territorial interactions occurred in the high-density treatment, improving their affective state. Our findings suggest that housing rainbow trout in small groups at high densities results in fish that are optimistic in novel situations, therefore in a more positive affective state than fish housed in small groups at low densities.

One limitation of our study was the time-intensive judgement bias training process. In order to be practically useful, judgment bias measures need to be easily attainable. We recommend further study into the modification of the judgement bias cues to be more biologically relevant. Perhaps utilizing access to conspecifics and social isolation as reward and punishment cues may allow for quicker training and a larger sample size for testing, however this has not yet been investigated.

Previous studies have found positive effects of tank complexity on performance parameters of rainbow trout ${ }^{45-48}$. In the present study, neither environmental complexity nor stocking density impacted body weight or length of fish. The lack of effect of the former could be due to the length of exposure to these enrichments. 
Vertically-suspended aluminum angles or rods with varying enrichment exposure duration (51, 61, 110, or 141 days) were associated with better trout weights, lengths, tank weight gain, and feed conversion ratio compared to trout housed in barren tanks ${ }^{46-49}$. Similarly, tanks with hanging colored plastic balls (for 70 or 127 days) showed improved tank weight gain, feed conversion ratio, and individual weight and lengths compared to trout housed without enrichments ${ }^{45,50}$. The previous work shows longer exposure times than the current study, which could be the reason for the lack of impact of complexity on production parameters in the current study.

The lack of effect of stocking density on production outcomes is somewhat in line with earlier findings ${ }^{51,52}$. For instance, rainbow trout reared at either 10,40 , or $80 \mathrm{~kg} / \mathrm{m}^{3}$ did not differ in growth rate ${ }^{53}$. Contrary to our findings, $70 \%$ of reviewed publications reported adverse effects of high densities (similar or higher than the density in the current study) on trout growth (see review ${ }^{54}$ ). For example, rainbow trout housed at $312 \mathrm{fish} / \mathrm{m}^{3}$ had the worst growth rate compared to trout housed at low densities of either $31,94,156$, or 250 fish $/ \mathrm{m}^{3}$ (compared to $165 \mathrm{fish} / \mathrm{m}^{3}$ versus $69 \mathrm{fish} / \mathrm{m}^{3}$ in the present study), with no differences in growth rate between the lower density levels ${ }^{55}$. Based on the judgement bias test responses in HD tanks and the lack of effects of stocking density on production outcomes, we can conclude that the high stocking density in this study was not detrimental to trout welfare or production up to day 96.

Feeding activity has been used widely as an observational indicator of fish welfare, as stressors can reduce feed intake and motivation to feed ${ }^{56}$. For instance, too low stocking densities decreased feed intake in rainbow trout ${ }^{7}$. We predicted that fish from HD tanks would have an increased motivation to feed, as increasing group size has shown to increase food-seeking behavior ${ }^{43}$. Our results conform to our predictions, as fish from HD tanks began feeding faster than fish from LD tanks (0.25s compared to $0.79 \mathrm{~s})$. This suggests that fish from HD tanks either had an increased motivation to feed or that fish from HD tanks were less stressed compared to fish from LD tanks. Although plasma cortisol concentrations did not significantly differ between stocking density treatments, numeric values do show a similar response compared to feeding behavior latencies, with fish from HD tanks having lower plasma cortisol than fish from LD tanks. This could imply that the fish from HD tanks were less stressed (lower cortisol) and more motivated to feed (shorter latencies to begin feeding) than fish from LD tanks, suggesting improved welfare.

Previous work on impacts of stocking density on cortisol levels show varying outcomes within and between studies. We hypothesized that fish from HC/HD tanks would have the lowest levels of plasma cortisol, as environmental complexity has been shown to reduce the impact of environmental stressors, while too low of stocking densities can result in higher stress levels ${ }^{57,58}$. Opposite to our predictions and to some previous work, treatments did not impact plasma cortisol levels. Atlantic salmon reared with plastic tubes or shredded black plastic bag enrichments had lower basal plasma cortisol levels than salmon reared in a barren environment (approximately $35 \mathrm{ng} / \mathrm{mL}$ compared to $10-15 \mathrm{ng} / \mathrm{mL}$ ) ${ }^{33}$. Rainbow trout reared at a low density of $134 \mathrm{~g} / \mathrm{L}$ (compared to $73.5 \mathrm{~g} / \mathrm{L}$ in the present study) showed higher plasma cortisol levels compared to fish reared at a high density of $277 \mathrm{~g} / \mathrm{L}$ (approximately $18 \mathrm{ng} / \mathrm{mL}$ versus $5 \mathrm{ng} / \mathrm{mL}$ ) ${ }^{58}$. Similarly, rainbow trout reared at $10 \mathrm{~kg} / \mathrm{m}^{3}$ showed higher plasma cortisol concentrations than trout reared at $80 \mathrm{~kg} / \mathrm{m}^{3}$ during 5 of the 9 sample timepoints ${ }^{53}$. Unstressed (control) brown trout (Salmo trutta) exhibited variable plasma cortisol concentrations, from approximately $20-70 \mathrm{ng} / \mathrm{mL}$ over the span of 8 hours ${ }^{59}$. In contrast, basal levels of plasma cortisol in unstressed salmonid fish have been reported to remain between $0-5 \mathrm{ng} / \mathrm{mL}^{60}$. This variation may, in addition to 
species and strain differences, be caused by the inconsistent nature of cortisol responses ${ }^{60-63}$, suggesting it may not be a reliable indicator for animal welfare.

This study is the first to establish the effect of environmental complexity and stocking density on judgement bias (optimism) in rainbow trout. Our results indicate that housing rainbow trout in relatively small groups at high densities from day 64 through 96 results in improved welfare status without any negative effects on performance parameters. The high stocking density level $\left(165 \mathrm{fish} / \mathrm{m}^{3}\right)$ used in this study resulted in more optimistic responses during the judgement bias test compared to fish in low-density environments, therefore suggesting a positive affective state in the former. Further confirmation of the beneficial effect of high density was the increased motivation to feed compared to fish housed at low densities. Therefore, trout feeding behavior shows potential as a feasible animal welfare indicator in a production setting, as it can be easily measured by aquaculture personnel. Monitoring changes in feeding behavior could be a useful indicator of a health or welfare issue. By housing rainbow trout in the density conditions described in this study and monitoring feeding behavior regularly, producers have the opportunity to rear fish under high welfare standards.

This study showed that a group approach to judgement bias training and testing resulted in differences between density treatments suggestive of a positive affective state for trout in high stocking densities. More research is needed on effective environmental enrichment and duration of exposure to enrichments for rainbow trout. With further investigation and modification of the test approach, judgement bias tests can be a valid indicator of affective state in rainbow trout.

\section{Declarations}

\section{Data availability}

The datasets generated and analyzed during the current study are available from the corresponding author upon reasonable request.

\section{Acknowledgements}

Special thanks to the Universities Federation for Animal Welfare for providing funding for the completion of this study. Thank you to Wytheville State Fish Hatchery for donating the animals. Thank you to Jireh Clarington, Alyssa Selhorst, and Margot Breiner for assistance with the project.

\section{Author contributions statement}

M.G.A. and L.J. designed and conducted the experiment together with S.A.S. and D.D.K. M.G.A., L.J. and A.M.C. performed statistical analysis on the data. M.G.A. and L.J. prepared the manuscript with assistance from S.A.S. and D.D.K. All authors have read and approved of the final manuscript.

\section{Additional information}

\section{Competing interests}

The authors declare no competing interests. 


\section{Data access}

Data used in this study are available upon reasonable request from the corresponding author.

\section{References}

1. Woynarovich, A., Hoitsy, G. \& Moth-Poulsen, T. Small-scale rainbow trout farming. FAO Fisheries and Aquaculture Technical Paper 81 (2011).

2. Newberry, R. C. Environmental enrichment: increasing the biological relevance of captive environments. Appl. Anim. Behav. Sci. 44, 229-243 (1995).

3. Gerber, B., Stamer, A. \& Stadtlander, T. Environmental Enrichment and its effects on Welfare in fish. (2015).

4. Bosakowski, T. \& Wagner, E. J. Experimental use of cobble substrates in concrete raceways for improving fin condition of cutthroat (Oncorhynchus clarki) and rainbow trout (O. mykiss). Aquaculture 130, 159-165 (1995).

5. Lee, J. S. F. \& Berejikian, B. A. Effects of rearing environment on average behaviour and behavioural variation in steelhead. J. Fish Biol. 72, 1736-1749 (2008).

6. Noble, C. et al. Welfare indicators for farmed rainbow trout: tools for assessing fish welfare. (2020).

7. Ellis, T. et al. The relationships between stocking density and welfare in farmed rainbow trout. J. Fish Biol. 61, 493-531 (2002).

8. Turnbull, J. F. et al. Stocking Density and the Welfare of Farmed Salmonids. in Fish Welfare (Blackwell Publishing Ltd, 2008). doi:10.1002/9780470697610.ch8.

9. Martins, C. I. M. et al. Behavioural indicators of welfare in farmed fish. Fish Physiology and Biochemistry vol. 38 17-41 (2012).

10. Pitcher, T. J. Functions of Shoaling Behaviour in Teleosts. in The Behaviour of Teleost Fishes (ed. Pitcher, T. J.) 294-337 (Springer US, 1986). doi:10.1007/978-1-4684-8261-4_12.

11. Relić, R. R., Hristov, S. V., Vučinić, M. M., Poleksić, V. D. \& Marković, Z. Z. Principles of fish welfare assessment in farm rearing conditions. J. Agric. Sci. 3, 273-282 (2010).

12. Ashley, P. J. \& Sneddon, L. U. Pain and fear in fish. in Fish welfare 46-77 (Oxford University Press, 2008).

13. Braithwaite, V. \& Boulcott, P. Can fish suffer? in Fish welfare 78-92 (Oxford University Press, 2008).

14. Crump, A., Bethell, E. J., Earley, R., Lee, V. E. \& Mendl, M. Emotion in animal contests. Proc. R. Soc. B, 277, Biol. Sci. e20201715 (2020) doi:10.1098/rspb.2020.1715.

15. Mendl, M., Burman, O. H. \& Paul, E. S. An integrative framework for the study of animal emotion and mood. Proc. R. Soc. B 277, 2895-2904 (2010).

16. Roelofs, S., Boleij, H., Nordquist, R. E. \& van der Staay, F. J. Making decisions under ambiguity: judgement bias tasks for assessing emotional state in animals. Front. Behav. Neurosci. 10, 119 (2016).

17. Kleinginna, P. R. \& Kleinginna, A. M. A categorized list of emotion definitions, with suggestions for a consensual definition. Motiv. Emot. 5, 345-379 (1981).

18. Dolcos, F. \& Denkova, E. Dissociating Enhancing and Impairing Effects of Emotion on Cognition. in Emerging Trends in the Social and Behavioral Sciences: An Interdisciplinary, Searchable, and Linkable 
Resource (eds. Scott, R. \& Kosslyn, S.) 1-18 (John Wiley \& Sons, Inc., 2015).

doi:10.1002/9781118900772.etrds0079.

19. Lazarus, R. S. Thoughts on the Relations Between Emotion and Cognition. Am. Psychol. 37, 1019-1024 (1982).

20. Paul, E. S., Harding, E. J. \& Mendl, M. Measuring emotional processes in animals: The utility of a cognitive approach. Neuroscience and Biobehavioral Reviews vol. 29 469-491 (2005).

21. Rogers, L., Sales, E., Shamsi, S., Kopf, R. K. \& Freire, R. Aggressive encounters lead to negative affective state in fish. PLoS One 15, e0231330 (2020).

22. Millot, S. et al. Use of conditioned place preference/avoidance tests to assess affective states in fish. Appl. Anim. Behav. Sci. 154, 104-111 (2014).

23. Cerqueira, M. et al. Cognitive appraisal of environmental stimuli induces emotion-like states in fish. Sci. Rep. 7, e13181 (2017).

24. Laubu, C., Louâpre, P. \& Dechaume-Moncharmont, F. X. Pair-bonding influences affective state in a monogamous fish species. Proc. R. Soc. B Biol. Sci. 286, e20190760 (2019).

25. Bethell, E. J. A “How-To” Guide for Designing Judgment Bias Studies to Assess Captive Animal Welfare. J. Appl. Anim. Welf. Sci. 18, S18-S42 (2015).

26. Baciadonna, L. \& McElligott, A. G. The use of judgement bias to assess welfare in farm livestock. Anim. Welf. 24, 81-91 (2015).

27. Mendl, M., Burman, O. H. P., Parker, R. M. A. \& Paul, E. S. Cognitive bias as an indicator of animal emotion and welfare: Emerging evidence and underlying mechanisms. Appl. Anim. Behav. Sci. 118, 161-181 (2009).

28. Harding, E. J., Paul, E. S. \& Mendl, M. Animal behaviour: cognitive bias and affective state. Nature 427, 312 (2004).

29. MacLeod, A. K. \& Byrne, A. Anxiety, depression, and the anticipation of future positive and negative experiences. J. Abnorm. Psychol. 105, 286-289 (1996).

30. Bateson, M. \& Nettle, D. Development of a cognitive bias methodology for measuring low mood in chimpanzees. PeerJ 3, e998 (2015).

31. Brockmark, S., Neregård, L., Bohlin, T., Björnsson, B. T. \& Johnsson, J. I. Effects of Rearing Density and Structural Complexity on the Pre- and Postrelease Performance of Atlantic Salmon. Trans. Am. Fish. Soc. 136, 1453-1462 (2007).

32. Näslund, J. \& Johnsson, J. I. Environmental enrichment for fish in captive environments: effects of physical structures and substrates. Fish Fish. 17, 1-30 (2016).

33. Näslund, J. et al. Hatchery tank enrichment affects cortisol levels and shelter-seeking in Atlantic salmon (Salmo salar). Can. J. Fish. Aquat. Sci. 70, 585-590 (2013).

34. Einfalt, L. M., Wojcieszak, D. B. \& Wahl, D. H. Behavior, Growth and Habitat Selection of Hatchery Esocids Reared with Artificial Vegetation. Trans. Am. Fish. Soc. 142, 345-352 (2013).

35. Gerasimov, Y. V. \& Stolbunov, I. A. Effect of environmental information richness during early development of bream (Abramis brama; Cyprinidae) upon feeding and defensive behavior of its yearlings. J. Ichthyol. 47, 246-253 (2007). 
36. Pickering, A. D., Griffiths, R. \& Pottinger, T. G. A comparison of the effects of overhead cover on the growth, survival and haematology of juvenile Atlantic salmon, Salmo salar L., brown trout, Salmo trutta L., and rainbow trout, Salmo gairdneri Richardson. Aquaculture 66, 109-124 (1987).

37. Nordgreen, J. et al. The time budget of Atlantic salmon (Salmo salar) held in enriched tanks. Appl. Anim. Behav. Sci. 144, 147-152 (2013).

38. Wojtas, K., Przemyslaw, C. P. \& Kolacz, R. Cognitive bias test as a tool for accessing fish welfare. Front. Mar. Sci. Conf. Abstr. XV Eur. Congr. Ichthyol. (2015) doi:10.3389/conf.fmars.2015.03.00200.

39. Bernstein, Y. \& Montgomery, W. L. Rainbow Trout (Oncorhynchus mykiss): A Technical Conservation Assessment.

http://www.fs.fed.us/r2/projects/scp/assessments/rainbowtrout.pdf[dateofaccess].ACKNOWLEDGMENTS (2008).

40. Becket, K. H. \& Barnes, M. E. Rearing with overhead cover influences rainbow trout behavior. Proc. S. Dak. Acad. Sci. 94, 187-193 (2015).

41. Kwain, W. \& MacCrimmon, H. R. Further observations on the response of rainbow trout, Salmo gairdneri, to overhead light. J. Fish. Res. Board Canada 26, 3233-3237 (1969).

42. Millidine, K. J., Armstrong, J. D. \& Metcalfe, N. B. Presence of shelter reduces maintenance metabolism of juvenile salmon. Funct. Ecol. 20, 839-845 (2006).

43. Johnsson, J. I. Group size influences foraging effort independent of predation risk: an experimental study on rainbow trout. J. Fish Biol. 63, 863-870 (2003).

44. Jenkins, T. M. Social structure, position choice and micro-distribution of two trout species (Salmo trutta and Salmo gairdneri) resident in mountain streams. Anim. Behav. Monogr. 2, 55-123 (1969).

45. Kientz, J. L., Crank, K. M. \& Barnes, M. E. Enrichment of circular tanks with vertically suspended strings of colored balls improves rainbow trout rearing performance. Am. J. Aquac. 80, 162-167 (2018).

46. Krebs, E., Huysman, N., Voorhees, J. M. \& Barnes, M. E. Suspended arrays improve rainbow trout growth during hatchery rearing in circular tanks. Int. J. Aquac. Fish. Sci. 4, 27-30 (2018).

47. White, S. C., Krebs, E., Huysman, N., Voorhees, J. M. \& Barnes, M. E. Use of suspended plastic conduit arrays during brown trout and rainbow trout rearing in circulars. N. Am. J. Aquac. 81, 101-106 (2019).

48. Huysman, N., Krebs, E., Voorhees, J. M. \& Barnes, M. E. Use of two vertically-suspended environmental enrichment arrays during rainbow trout rearing in circular tanks. Int. J. Innov. Stud. Aquat. Biol. Fish. 5, 2530 (2019).

49. Kientz, J. L. \& Barnes, M. E. Structural complexity improves the rearing performance of rainbow trout in circular tanks. N. Am. J. Aquac. 78, 203-207 (2016).

50. Crank, K. M., Kientz, J. L. \& Barnes, M. E. An evaluation of vertically suspended environmental enrichment structures during rainbow trout rearing. N. Am. J. Aquac. 81, 94-100 (2019).

51. Kebus, M. J. et al. Effects of rearing density on the stress response and growth of rainbow trout. J. Aquat. Anim. Health 4, 1-6 (1992).

52. Wagner, E. J., Intelmann, S. S. \& Routledge, M. D. The effects of fry rearing density on hatchery performance, fin condition, and agonistic behavior of rainbow trout Oncorhynchus mykiss fry. J. World Aquac. Soc. 27, 264-274 (1996). 
53. North, B. P. et al. The impact of stocking density on the welfare of rainbow trout (Oncorhynchus mykiss). Aquaculture 255, 466-479 (2006).

54. Ellis, T. et al. The relationships between stocking density and welfare in farmed rainbow trout. J. Fish Biol. 61, 493-531 (2002).

55. Papoutsoglou, S. E., Papaparaskeva-Papoutsoglou, E. \& Alexis, M. N. Effect of density on growth rate and production of rainbow trout (Salmo gairdneri Rich.) over a full rearing period. Aquaculture 66, 9-17 (1987).

56. Martins, C. I. M. et al. Behavioural indicators of welfare in farmed fish. Fish Physiol. Biochem. 38, 17-41 (2012).

57. Pounder, K. C., Mitchell, J. L., Thomson, J. S., Pottinger, T. G. \& Buckley, J. Does environmental enrichment promote recovery from stress in rainbow trout? Appl. Anim. Behav. Sci. 176, 136-142 (2016).

58. Leatherland, J. F. \& Cho, C. Y. Effect of rearing density on thyroid and interrenal gland activity and plasma and hepatic metabolite levels in rainbow trout, Salmno gairdneri Richardson. J. Fish Biol. 27, 583-592 (1985).

59. Pickering, A. D., Pottinger, T. G. \& Christie, P. Recovery of the brown trout, Salmo trutta L., from acute handling stress: a time-course study. J. Fish Biol. 20, 229-244 (1982).

60. Pickering, A. D. \& Pottinger, T. G. Stress responses and disease resistance in salmonid fish: effects of chronic evaluation of plasma cortisol. Fish Physiol. Biochem. 7, 253-258 (1989).

61. Woodward, C. C. \& Strange, R. J. Physiological stress responses in wild and hatchery-reared rainbow trout. Trans. Am. Fish. Soc. 116, 574-579 (1987).

62. Rance, T. A., Baker, B. I. \& Webley, G. Variations in plasma cortisol concentrations over a 24-hour period in the rainbow trout Salmo gairdneri. Gen. Comp. Endocrinol. 48, 269-274 (1982).

63. Bry, C. Daily variations in plasma cortisol levels of individual female rainbow trout Salmo gairdneri: evidence for a post-feeding peak in well-adapted fish. Gen. Comp. Endocrinol. 48, 462-468 (1982).

64. Ausseil, O. Recommended biological and water quality limits for trout fishery and trout spawning waters in the Wellington Region. http://www.gw.govt.nz/assets/Plans--Publications/Regional-Plan-Review/FINALREPORT-Instream-objectives-to-protect-trout-fishery-and-spawning-values-June-2013.PDF (2013).

65. Cline, D. Water Quality in Aquaculture. Freshwater Aquaculture https://freshwateraquaculture.extension.org/water-quality-in-aquaculture/ (2019).

66. AVMA Guidelines for the Euthanasia of Animals: 2020 Edition. (2020).

\section{Tables}

Table 1. Mean latency for the first fish to enter ( $s \pm$ standard error) each chamber during the judgement bias test for trout in either high- or low-complexity tanks ( $n=8$ tanks; 38 fish).

\begin{tabular}{|llllll|}
\hline \multirow{2}{*}{ Complexity level } & \multicolumn{5}{l}{ Mean latency $(\mathrm{s})$ for the first fish to enter $(\mathrm{LSM} \pm$ SEM) } \\
\cline { 2 - 6 } & POS & NP & MID & NN & NEG \\
\hline High & $11.56 \pm 1.69$ & $11.17 \pm 2.75$ & $10.41 \pm 2.76$ & $12.09 \pm 2.33$ & $13.39 \pm 2.45$ \\
\hline Low & $11.01 \pm 1.69$ & $9.87 \pm 2.75$ & $8.78 \pm 2.76$ & $15.43 \pm 2.33$ & $14.60 \pm 2.45$ \\
\hline
\end{tabular}


Table 2. Overview of judgement bias training and testing approach for rainbow trout during days 13-95. Fish (n $=5$ tanks; 108 fish) were trained to associate a positive reward (handful of feed) with the POS chamber and a negative punishment ( $1 \mathrm{~s}$ chase by net) with the NEG chamber. A subsample of fish ( $n=2$ tanks; 38 fish) moved on to the reminder training and testing phases.

\begin{tabular}{|c|c|c|c|c|c|c|}
\hline \multirow{3}{*}{$\begin{array}{l}\text { Judgement } \\
\text { bias phase }\end{array}$} & \multirow{3}{*}{$\begin{array}{l}\text { Objective } \\
\text { Acclimate fish to } \\
\text { arena in groups of } \\
\sim 21\end{array}$} & \multirow{3}{*}{$\begin{array}{l}\text { Day }^{1} \\
\text { 13- } \\
31\end{array}$} & \multicolumn{2}{|c|}{$\begin{array}{l}\text { Maximum } \\
\text { duration/ } \\
\text { session (min) }\end{array}$} & \multirow{2}{*}{$\begin{array}{l}\text { Attempts/ } \\
\text { session } \\
\text { (n) } \\
1\end{array}$} & \multirow[t]{3}{*}{ Measurements } \\
\hline & & & $\begin{array}{l}\text { Sessions } \\
1-4\end{array}$ & 5 & & \\
\hline & & & $\begin{array}{l}\text { Sessions } \\
5-9\end{array}$ & 15 & 1 & \\
\hline 1 & $\begin{array}{l}\text { Associate POS } \\
\text { chamber with reward } \\
\text { in groups of } \sim 21\end{array}$ & $\begin{array}{l}32- \\
58\end{array}$ & 5 & & 12 & $\begin{array}{l}\text { Fish that entered chamber } \\
\text { (n), fish feeding }(\mathrm{y} / \mathrm{n})\end{array}$ \\
\hline $1 \mathrm{~A}$ & $\begin{array}{l}\text { Autoshaping in } \\
\text { groups of } \sim 21\end{array}$ & $\begin{array}{l}39- \\
57\end{array}$ & 5 & & 12 & $\begin{array}{l}\text { Fish that oriented towards } \\
\text { or entered chamber }(n) \text {, } \\
\text { fish feeding }(n)\end{array}$ \\
\hline 2 & $\begin{array}{l}\text { Enter POS chamber } \\
\text { while in groups of } \\
\sim 10\end{array}$ & $\begin{array}{l}49- \\
59\end{array}$ & 5 & & 12 & $\begin{array}{l}\text { Fish that entered the } \\
\text { chamber }(n) \text {, fish feeding } \\
\text { (n), latency of first fish to } \\
\text { enter (s) }\end{array}$ \\
\hline 3 & $\begin{array}{l}\text { Associate NEG } \\
\text { chamber with } \\
\text { punishment }\end{array}$ & $\begin{array}{l}59- \\
61\end{array}$ & 2.5 & & 6 & $\begin{array}{l}\text { Latency for the first fish to } \\
\text { enter (s) }\end{array}$ \\
\hline $\begin{array}{l}\text { Reminder } \\
\text { training }^{2}\end{array}$ & $\begin{array}{l}\text { Reinforce NEG and } \\
\text { POS chamber } \\
\text { responses }\end{array}$ & $\begin{array}{l}71 \\
79 \\
88\end{array}$ & 2.5 & & 6 & $\begin{array}{l}\text { Latency for the first fish to } \\
\text { enter }(s)\end{array}$ \\
\hline Testing ${ }^{2}$ & $\begin{array}{l}\text { Record responses to } \\
\text { ambiguous cues }\end{array}$ & $\begin{array}{l}92 \\
93 \\
95\end{array}$ & 4 & & 7 & $\begin{array}{l}\text { Latency for the first fish to } \\
\text { enter (s) }\end{array}$ \\
\hline
\end{tabular}

${ }^{1}$ From start of the phase until the last tank met the learning criterion for that phase

${ }^{2}$ Occurred after fish were allocated to their treatment groups

\section{Figures}




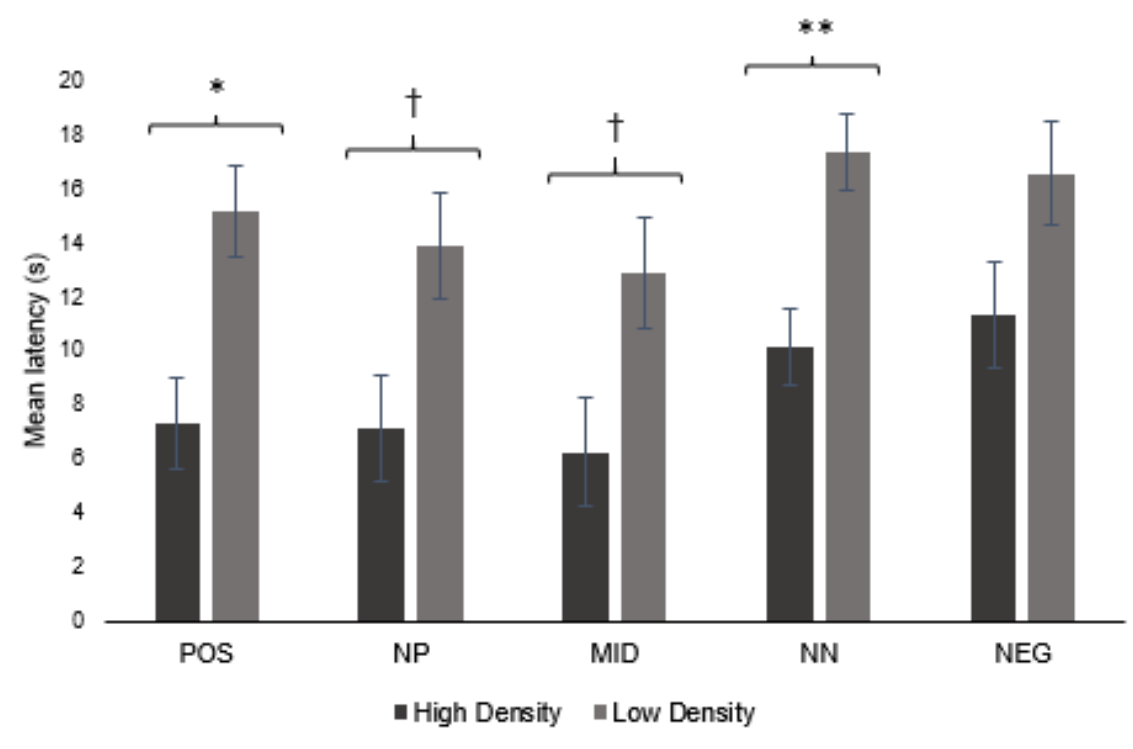

\section{Figure 1}

Mean latency for the first fish to enter (seconds) each chamber during the judgement bias test for trout housed under high or low stocking density ( $\mathrm{n}=8$ tanks; 38 fish). ${ }^{\star} * \mathrm{P}<0.01$; ${ }^{*} \mathrm{P}<0.05$; $\mathrm{P}<0.1$.

350

300

250

200

150

100

50

0

0

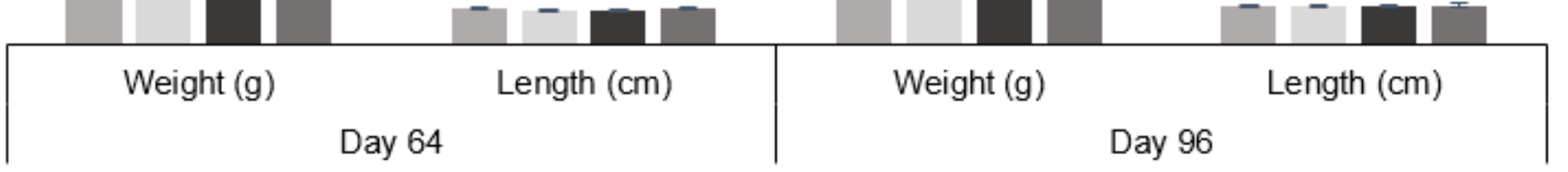

«igh Complexity $\quad$ Low Complexity $\quad$ High Density $\quad$ Low Density

\section{Figure 2}

Mean weight $(\mathrm{g})$ and length $(\mathrm{cm}) \pm$ standard error of fish from each treatment group, measured on days 64 ( $\mathrm{n}=$ 68) and $96(n=66)$. 
1

a

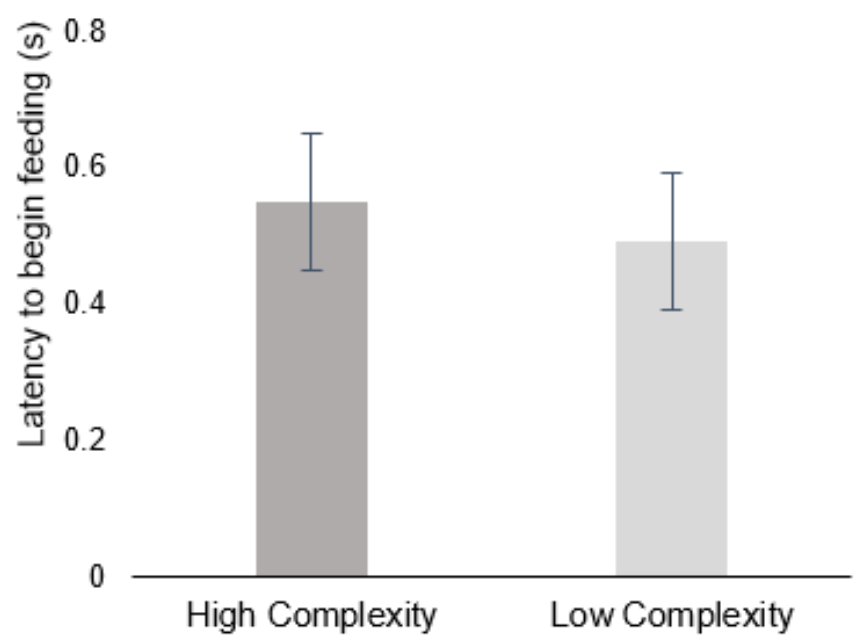

1

b

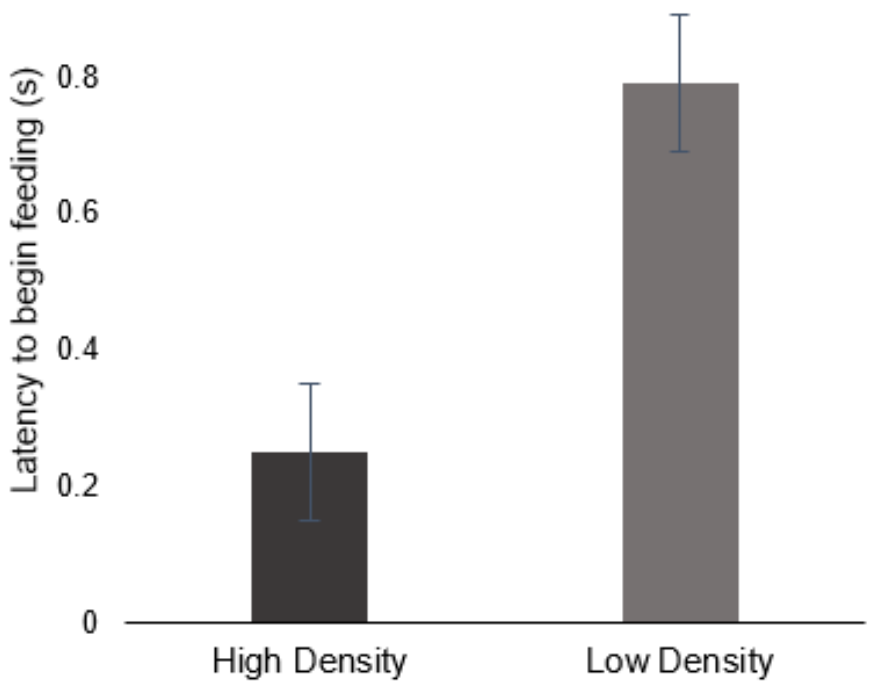

\section{Figure 3}

Mean latencies for the first fish to begin feeding (seconds) during daily feedings on days 79-95 for fish housed in a) high- or low-complexity tanks or b) high or low stocking density tanks (observation $\mathrm{n}=128$ ).

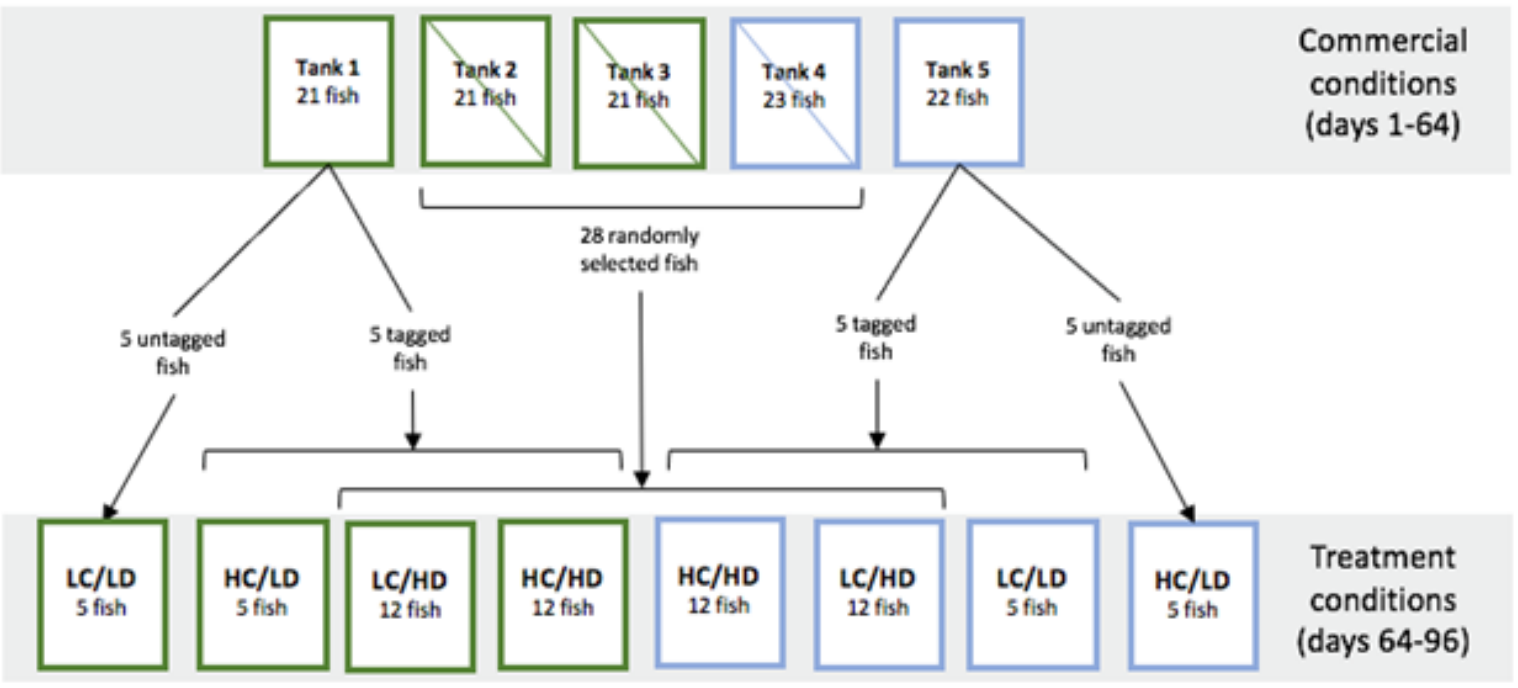

Figure 4

Overview of housing conditions and fish distribution throughout the experiment. Tanks in green were trained with the positive cue on the far left of the judgement bias arena, while tanks in blue were trained with the positive cue on the far right. Tanks with fish that did not pass phase 3 learning criterion are crossed with a diagonal line. $\mathrm{LC}=$ low complexity, $\mathrm{HC}=$ high complexity, $\mathrm{LD}=$ low density, $\mathrm{HD}=$ high density treatments. 


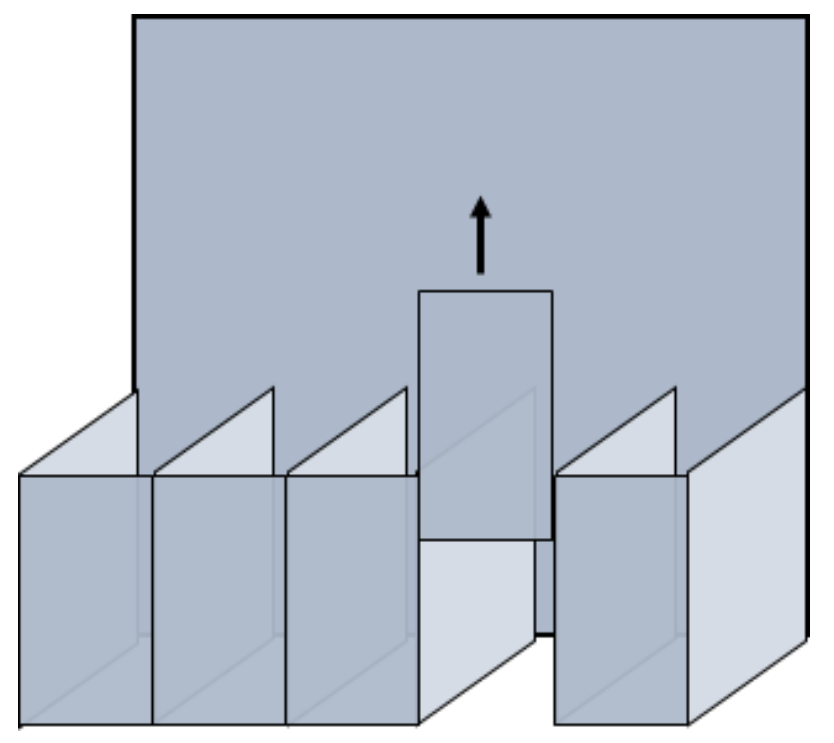

\section{Figure 5}

Diagram of the judgement bias arena. Positive (POS) and negative (NEG) chambers were balanced across tanks $(n=8)$. The middle three ambiguous chambers were introduced during testing. Entrance into each chamber was allowed by opening a sliding plexiglass door. 